\title{
Homilías
}

\section{Undécimo primer aniversario del asesinato de los padres jesuitas}

No podemos pasar desapercibida una fecha como ésta, pues son efemérides eclesiales que forman parte de nuestra historia y que quedarán impresas no sólo en nuestros libros de historia eclesial, sino en nuestros corazones y en nuestras mentes, pues testimonios como éstos nos deben seguir alimentando en toda nuestra vida, lo hemos repetido muchas veces y de ello estamos completamente persuadidos, lo que más falta nos hace en estos tiempos es testimonio de hombres y mujeres de fe profunda que nos animen a seguir a Jesús cada día de nuestra vida hasta la muerte. Por esa razón, esta noche estamos aquí para demostrar que de nuestra parte estamos dispuestos a continuar viviendo nuestra fe $y$ a seguir trabajando con todas nuestras fuerzas en la construcción del reino en nuestro querido El Salvador.

1. El martirio en el contexto del gran jubileo

El papa Juan Pablo II ha insistido, durante su pontificado, en la importancia que tiene el martirio en la vida de la Iglesia de hoy día. Siempre destacamos la importancia de la Iglesia martirial de los primeros siglos del cristianismo, pero poco hemos profundizado en lo que el martirio significa para la Iglesia de cualquier época como parte de su identidad, de su quehacer cotidiano, como algo que la acompaña siempre como lo anunció Jesús en las bienaventuranzas. "Bienaventurados los que fuesen perseguidos por causa de la justicia, porque de ellos es el reino de Dios" (Mt 5, 10).

En la bula de convocación del gran jubileo del año 2000 (Incarnationis Mysterium), el Papa destaca algunos signos propios del año jubilar, entre ellos destaca la memoria de los mártires, donde nos pide, en primer lugar, que no hay que olvidar a nuestros mártires, pues "ellos son los que han anunciado el evangelio dando su vida por amor. El mártir, sobre todo en nuestros días, es 
signo de este amor más grande que compendia cualquier otro valor" (IM, 13).

El Papa nos quiere invitar a tener en cuenta que el martirio es una posibilidad anunciada por la revelación y no podemos excluir esta perspectiva en nuestro propio horizonte existencial, y la historia es un testimonio de esta verdad. En todas las épocas se encuentran hombres y mujeres de fe que han ofrendado martirialmente sus vidas por causa del evangelio, y el documento papal que comentamos dice textualmente en relación a esto: "Personas de todas las clases sociales han sufrido por su fe, pagando con la sangre su adhesión a Cristo y a la Iglesia, o soportando con valentía largos años de prisión y de privaciones de todo tipo por no ceder a una ideología transformada en un régimen dictatorial despiadado" (IM, 13).

Por lo tanto, el martirio es el testimonio más fuerte de fe y de adhesión a Jesucristo y gracias a esa adhesión el creyente es capaz de arriesgarlo todo, hasta la propia vida, pues esos valores emanados de la propia ve, lo mueven a permanecer firme en sus principios y valores aunque ello le implique el máximo sacrificio: dar la vida por su fe. Desde luego que esta opción es profunda y coherente con toda una manera de vivir y de pensar, pues los mártires no se improvisan, llevan una vida tal que se van preparando espiritualmente para asumir, en circunstancias especiales, las opciones que sean necesarias para cumplir las metas que cada uno se ha trazado. Esto quiere decir que cada día podemos ir preparando nuestro propio martirio, luchando tenazmente por aquellos valores evangélicos que nos son esenciales como discípulos de Jesús: el amor a los pobres, la sinceridad, la humildad, la coherencia, el desprendimiento, la fidelidad, la obediencia, el desprendimiento de las cosas materiales, el espíritu de sacrificio, la solidaridad efectiva con los excluidos del momento, etc. De esta manera, la vida misma se vuelve una escuela de mártires, siempre y cuando la sepamos vivir con intensidad, con gozo, con esperanza, con una auténtica pobreza espiritual. Este camino es un camino duro, sacrificado, austero, pero lleno de compensaciones espirituales y morales: los verdaderos santos son felices incluso en medio de todas sus limitaciones y pobrezas, porque saben para qué viven, porqué trabajan, jamás dan lugar a la tristeza, a la desesperanza, a la angustia... en definitiva, saben luchar y conocen muy bien su misión y la llevan a cabo de la mejor manera y hasta las últimas consecuencias.

El libro del Apocalipsis, en el capítulo 7, verso 14, nos dice: "han lavado sus vestiduras y las han blanqueado con la sangre del Cordero"... y el Papa en la Incamationis Mysterium (N 13) dice: "Por eso la Iglesia, en todas las partes de la tierra, debe permanecer firme en su testimonio y defender celosamente su memoria. Que el pueblo de Dios, fortalecido en su fe por el ejemplo de estos auténticos paladines de todas las edades, lenguas y naciones, cruce con confianza el umbral del tercer milenio. Que la admiración por su 
martirio esté acompañada, en el corazón de los fieles, por el deseo de seguir su ejemplo, con la gracia de Dios, si así lo exigieran las circunstancias" (IM, 13).

Es hermoso reconocer desde nuestra propia historia salvadoreña, que hemos enriquecido las páginas de la historia de la Iglesia con un buen número de hombres y mujeres, obispos, sacerdotes, religiosas y laicos que tan valientemente han dejado huella con una vida auténticamente cristiana y con una muerte violenta aceptada con amor a causa de su fe y de sus principios evangélicos. Y con ellos podemos ahora nosotros, los que aún vivimos, cruzar con mayor esperanza los umbrales del tercer milenio. Su testimonio nos anima a continuar con una vida de fe, de servicio, de entrega generosa a las causas más nobles de nuestra Iglesia, y por la construcción de un mundo más justo y solidario, donde verdaderamente se respete la dignidad de todos los hombres y mujeres y donde se practique una verdadera democracia, que dé la oportunidad a todos de vivir con dignidad y en verdadera fraternidad.

El martirio es el testimonio más fuerte de fe y de adhesión a Jesucristo y gracias a esa adhesión el creyente es capaz de arriesgarlo todo, hasta la propia vida, pues esos valores emanados de la propia fe, lo mueven a permanecer firme en sus principios y valores aunque ello le implique el máximo sacrificio: dar la vida por su fe.

2. Las lecciones que hemos recibido del martirio de los padres jesuitas y de sus dos colaboradoras

Antes de puntualizar las lecciones que nos dejan, quiero decirles que personalmente tuve la suerte de conocer a los seis sacerdotes asesinados hace once años, en los alrededores del campus universitario, y quiero testimoniar que siempre he estado cerca de los padres jesuitas. Fui formado por ellos en el Seminario Mayor de San José de la Montaña y allí tuve la oportunidad de conocerlos cuando eran jóvenes sacerdotes, y luego siempre he seguido de cerca su trabajo y sus grandes esfuerzos por ayudar a este pueblo salvadoreño a salir del subdesarrollo y de la dependencia estructural que lo ata. He admirado su trabajo, y su muerte martirial vino a poner de relieve su altura humana $y$ cristiana y su gran disponibilidad para hacer la voluntad de Dios. Volviendo al tema de las lecciones que todos debemos asumir, trataré de resumirlas de la siguiente manera.

(a) Los mártires no sólo nos interpelan, sino que, además, son punto de referencia obligatorio y fuerza para continuar ( $C$ fr. $E C A$, noviembre-diciembre, 1999, p. 972). Frente a su testimonio, ni pastores, ni laicos podemos 
permanecer indiferentes ante tanta injusticia que aún nos aqueja en el país. Los datos son alarmantes y la extrema pobreza ya golpea casi a un 70 por ciento de la población. Los que estamos en contacto con las comunidades, principalmente rurales y marginadas, nos duele el alma de ver cada día muchos cuadros de verdadera miseria, donde falta todo: sin techo, sin pan en la mesa, sin ropa, sin medicinas, sin educación, sin futuro, sin esperanza... Es desgarrador y el ejemplo de valentía y tenacidad de los padres asesinados, nos deben empujar a dar la mano cada día a todos los que la pidan.

(b) Su recuerdo siempre ha sido una forma eficaz de resistencia y de protesta ante las injusticias y violencias pasadas y presentes. Nuestra pasividad nos hace cómplices de tanta miseria humana, urge, pues, que busquemos juntos, pastores y laicos, las formas más eficaces de expresar nuestro desacuerdo y nuestra protesta por tanta violación a los derechos más elementales de los más pobres. Monseñor Romero fue la voz de los que no tenían voz... y ahora, ¿quiénes los vamos a relevar? Los padres jesuitas asesinados se sumaron en su tiempo a luchar a favor de los sin voz y sin esperanza, y ello les acarreó tantos insultos y calumnias y, finalmente, la muerte. Hoy debemos buscar creativamente las formas más eficaces para expresar nuestro malestar y abrir caminos para que los pobres mismos puedan expresarse, a través de un proceso permanente de organización y de solidaridad con todas las fuerzas vivas de la sociedad salvadoreña, que no están de acuerdo con la situación que vivimos.

(c) Su recuerdo es también anuncio de una utopía y actualización de la esperanza, en cuanto mantiene vivo el ideal de una sociedad plenamente humana, fraterna y solidaria.

El pensamiento y la política neoliberal carecen de utopías. El único horizonte abierto para estos nuevos artífices sociales es el enriquecimiento sin límites de unos cuantos ricos y la condena, sin ningún miramiento, de la inmensa mayoría de la población a vivir en la extrema pobreza, excluida de toda participación en todos los campos de la vida social. Lo que importa para ellos es producir, vender, consumir, acumular y así competir en el mundo globalizado. Llegar a tener es la única utopía posible y, en muchos casos, no importa por qué medios.

Como cristianos y siguiendo el testimonio de nuestros mártires, nosotros tenemos utopías y una fuerte esperanza de que algún día este pueblo saldrá de su miseria y de su dependencia y que alcanzaremos la verdadera libertad, la verdadera justicia y una paz duradera. Lo importante es no postergar el inicio de nuestra lucha. Podemos comenzar hoy mismo.

(d) Nos enseñaron a bajar de la cruz al pueblo crucificado, tal como lo expresó muchas veces el padre Ignacio Ellacuría. ¿De qué manera lo hacían? Principalmente formando seria y disciplinadamente a las nuevas generacio- 


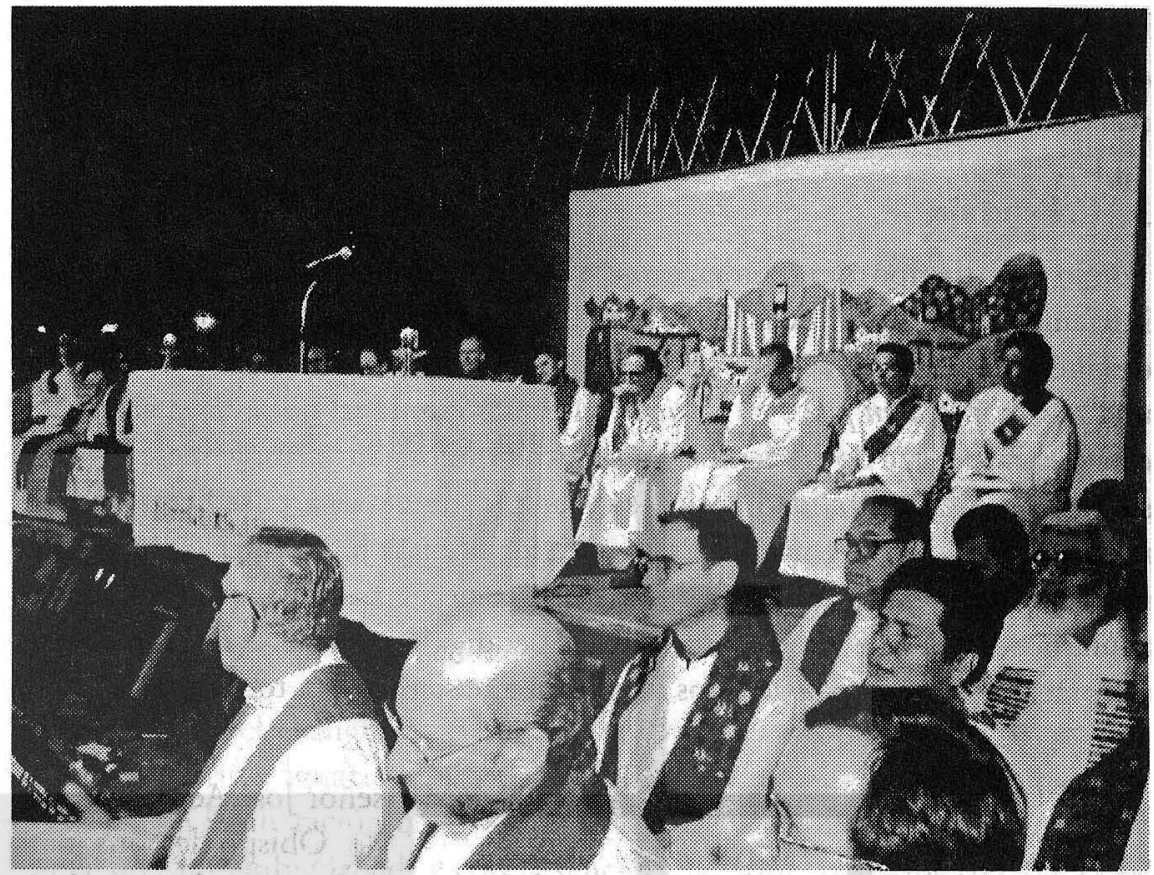

nes, trabajando duramente en las aulas y sacando de la ignorancia a tanto joven que es presa del sistema, quienes habían alienado su conciencia a principios ajenos a la vida cristiana; lo hicieron participando en muchas actividades populares, en publicaciones, en formación de grupos solidarios, en comunidades donde ellos realizaban labores pastorales, lo hicieron asesorando a líderes comunitarios y políticos, que creían en sus enseñanzas. De esta manera, muchos pudieron bajar de la cruz y seguir su camino hacia su plena liberación.

(e) Nos comunican una luz que penetra en el corazón y en la mente de quienes los admiramos como hombres de fe y verdaderos discípulos de Jesús.

En este momento, nuestra historia patria está llena de tinieblas, violencia indiscriminada, irrespeto a los derechos fundamentales, principalmente de niños, niñas y mujeres, que son frecuentemente maltratados, violencia intrafamiliar, secuestros, corrupción a todos los niveles, y la pobreza extrema que cada día se profundiza más y más. Por otra parte, las tinieblas penetran en muchas instancias que deberían luchar por el bien del pueblo, pero que ceden y traicionan los principios para las que fueron creadas.

Su testimonio es una luz en la oscuridad y nos señalan el camino a seguir y a nunca perder la esperanza. Nos enseñan que solo unidos, pastores y laicos, unidos maestros y estudiantes, unidas las organizaciones populares, unidas todas las gremiales que apoyan la verdadera democracia, en fin, unidas todas las fuerzas vivas y democráticas de este país, podremos alcanzar el 
ideal por el que ellos tanto lucharon: una verdadera civilización del amor, una auténtica democracia donde todos se sientan respetados en sus derechos fundamentales, donde todos podamos convivir como hermanos.

\section{Conclusión}

No hay tiempo que perder, urge que levantemos nuestro espíritu y que iniciemos una nueva lucha para reivindicar a todos aquellos que durante y después del conflicto armado salvadoreño, ofrendaron sus vidas para alcanzar una patria nueva en paz y en justicia. Mientras este ideal no se haya alcanzado en nuestra patria, no podemos dormir tranquilos. Su ejemplo de sacrificio, su ejemplo de sensibilidad social, su ejemplo de entrega a las causas nobles nos deben animar a nunca detenernos. Que el señor Jesús, al celebrar sus dos mil años de encarnación, nos dé las fuerzas necesarias para cumplir lo que ahora nos toca a nosotros. Que Dios los bendiga por su participación en esta celebración y que la paz de Dios los acompañe siempre en todas partes.

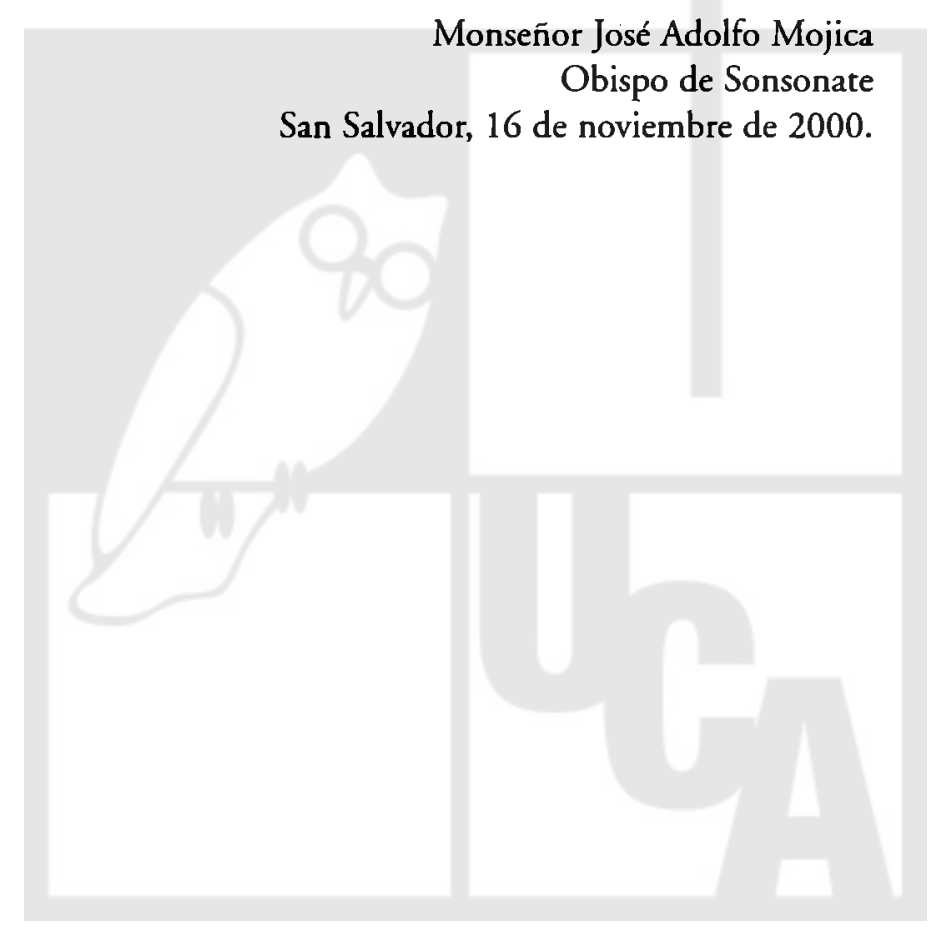

